\title{
Application of Ion Chromatography for Determining Trace Lead(II) and Cadmium(II) Stabilizers in Electroless Plating Baths
}

\author{
M. U. Mahmud, J. Bains and D. Cote \\ Nashua Corporation, 44 Franklin Street, Nashua, NH 03061, USA
}

Lead and cadmium salts are widely used as stabilizers for the electroless plating bath. The concentrations of these stabilizers, though relatively small, i.e., between 0.5-1.0 ppm, have a great influence on the performance and the rate of plating. Therefore, these components of the bath are routinely monitored accurately by various instrumental analyses including ion chromatography. ${ }^{1-8}$

Among these techniques, ion chromatography is relatively new. It is only since 1982 that it has been possible to analyze transition metals by employing this technique. The methods described by Dionex Corporation for the analysis of transition metals are only satisfactory for most applications where the concentrations of the stabilizers and other metals do not differ widely. ${ }^{2,7}$ However, the matrix interferences and low sensitivity for lead(II) and cadmium(II) make the detection of these elements at trace levels very difficult in electroless plating baths with ion chromatography.

In order to overcome these difficulties, Heberling $e t$ al. at Dionex recently developed a mixed bed latex column (CS-5) to detect trace metals such as lead(II) and cadmium(II) in electroless nickel plating baths. ${ }^{1}$ These authors have demonstrated the separation of $\mathrm{Cu}$ (II) at the $20 \mathrm{ppb}$ and $\mathrm{Pb}(\mathrm{II})$ and $\mathrm{Cd}(\mathrm{II})$ at the 100 ppb levels.

We have taken a different approach to resolve the problem. Instead of using the mixed bed latex column, which was not available at the time of our investigation, we modified the original Dionex method and chromatographic system and achieved detection of $\mathrm{Pb}$ (II) and $\mathrm{Cd}(\mathrm{II})$ at levels as low as $100 \mathrm{ppb}$.

In this paper, we have discussed the instrument modification that overcomes both matrix interference and overloading of the column in the analysis of stabilizers in electroless plating baths.

\section{Experimental}

The analyses were carried out by using a Dionex 2020 i series Ion Chromatograph with a post column membrane reactor and UV/VIS detector operated at a wavelength of $520 \mathrm{~nm}$. The separation of the bath components was accomplished by using two 4.0 $\mathrm{mm} \times 25 \mathrm{~cm}$ Dionex AS-3 separator columns. A 4.0 $\mathrm{mm} \times 5.0 \mathrm{~cm} \mathrm{AG}-3$ guard column was also used. The eluent was $0.05 \mathrm{M}$ oxalic acid with the $\mathrm{pH}$ adjusted to 4.6 with lithium hydroxide. The eluent flow rate was $1.0 \mathrm{ml} / \mathrm{min}$. The post column reactant was $4.0 \times 10^{-4} \mathrm{M}$ 4-(2-pyridylazo) resorcinol, monosodium salt which was made up in a mixture of $3.0 \mathrm{M}$ ammonium hydroxide and $1.0 \mathrm{M}$ acetic acid solution. The reactant flow rate was maintained at $0.6 \mathrm{ml} / \mathrm{min}$. The samples were prepared by diluting the bath solution in the proportion of $1: 1$ with $0.05 \mathrm{M}$ oxalic acid eluent. The lead and cadmium standards were prepared from atomic absorption standard stock solutions (Alfa products) by diluting with $0.05 \mathrm{M}$ oxalic acid eluent. The sample injection size was $10 \mu \mathrm{l}$ in all cases and the detector sensitivity was 0.10 AUFS.

Data was collected on a Spectra Physics Model 4270 integrator, and the peak height was used for quantitation.

All reagents listed were obtained from Aldrich Chemical Co. with the exception of the ammonium hydroxide and glacial acetic acid (reagent grade) which were obtained from J. T. Baker.

\section{Results and Discussion}

The preliminary analyses of electroless plating baths to identify the stabilizers were carried out by following the operating conditions recommended by Dionex for standard transition metal analysis, as shown in Table 1. In the process, we encountered two major obstacles. They were as follows:

i) The major components of the bath such as $\mathrm{Ni}$ (II) and Co(II) overloaded the column because of the low column capacity, Fig. 1 (a).

ii) When the sample was diluted, there was inadequate sensitivity to detect $\mathrm{Pb}$ (II) and $\mathrm{Cd}(\mathrm{II})$ at such low concentrations, Fig. 1 (b).

Methods using single AS-3 and AS-4 columns (Dionex Corporation) were also investigated extensively by varying eluents, dilution and flow rate. However, none of these variations allowed us to observe the separation of $\mathrm{Pb}$ (II) and $\mathrm{Cd}$ (II) from the other components of the electroless plating baths. This is primarily because the excess amounts of other transition metals present in the bath interfere with such separation. Application of two higher efficiency AS- 4 columns was ruled out because of the higher back 
Table 1 Ion chromatographic conditions for the analysis of electroless plating baths for lead(II) and cadmium(II)

\begin{tabular}{|c|c|}
\hline Instrument & Dionex $2020 \mathrm{i}$ \\
\hline Pump & System II \\
\hline Flow rate & $1.0 \mathrm{ml} / \mathrm{min}$ \\
\hline Eluent program & $\begin{array}{l}0.05 \mathrm{M} \text {. oxalic acid is adjusted to a } \mathrm{pH} \\
\text { of } 4.6 \text { with lithium hydroxide. At run } \\
\text { time } 15 \text { min switch to } 0.25 \mathrm{M} \text { oxalic } \\
\text { acid (to flush the nickel through the } \\
\text { column). At run time } 35 \text { min begin } \\
\text { column re-equilibration with } 0.050 \mathrm{M} \\
\text { eluent. At run time } 50 \text { min the system } \\
\text { is ready for injection of next sample. }\end{array}$ \\
\hline Reactant & $\begin{array}{l}4.0 \times 10^{-4} \mathrm{M} \text {. PAR reagent in } 3.0 \mathrm{M} \text { am- } \\
\text { monium hydroxide and } 1.0 \mathrm{M} \text { acetic } \\
\text { acid. }\end{array}$ \\
\hline Reactant flow rate & $0.6 \mathrm{ml} / \mathrm{min}$ \\
\hline Column & $\begin{array}{l}\text { HPIC AG-3 guard column with } 2 \\
\text { HPIC AS-3 separator } \\
\text { columns connected in series. }\end{array}$ \\
\hline Detectors & $\begin{array}{l}\text { Dionex UV/VIS at } 520 \mathrm{~nm} \text { with filter } \\
\text { No. } 7\end{array}$ \\
\hline Sensitivity & 0.10 AUFS \\
\hline Attenuation & $\times 512$ \\
\hline
\end{tabular}

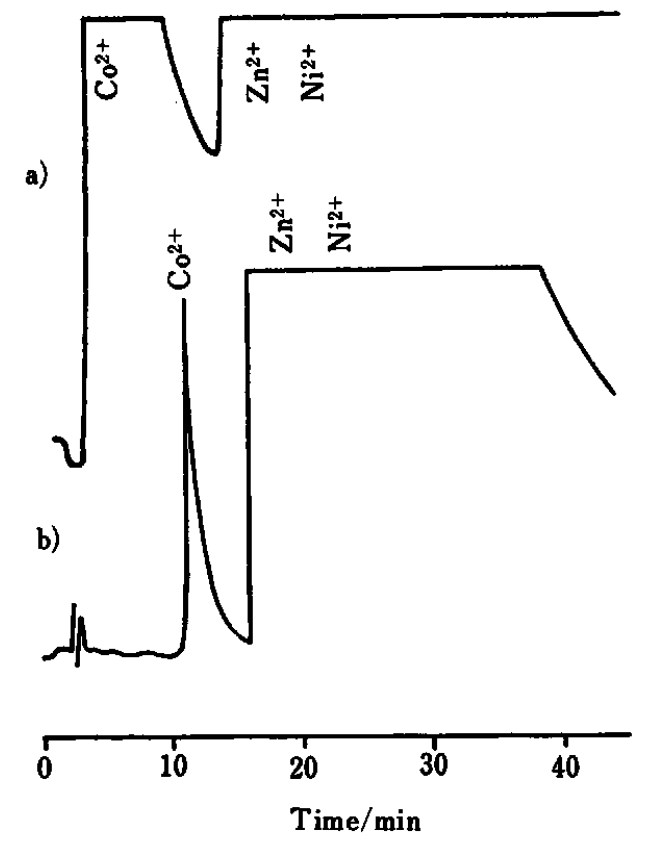

Fig. 1 (a) Ion chromatogram of electroless plating bath solution using quaternary ammonium anion exchange column (AS-3). (b) Ion chromatogram of diluted electroless plating bath solution using quaternary ammonium anion exchange column (AS-3). Sample has been diluted 1:10 instead of $1: 1$ and run through the instrument without the column flush or reactor by-pass. pressure asociated with these columns.

Subsequently, in order to obtain additional capacity, we connected two AS-3 columns in a series. The chromatogram thus obtained is presented in Fig. 2 (a), which illustrates that both $\mathrm{Pb}$ (II) and $\mathrm{Cd}(\mathrm{II})$ are completely separated from the major components of the bath. The ions have been identified by comparing the retention times of the standard stock solutions of $\mathrm{Pb}$ (II) and $\mathrm{Cd}$ (II) to those of the retention times of the peaks observed for the bath solution, Fig. $2(b, c)$. We also verified the peak position by adding $0.5 \mathrm{mg} / 1$ of $\mathrm{Pb}$ (II) or $\mathrm{Cd}$ (II) to the sample of the electroless bath solution. The chromatogram obtained on addition of $\mathrm{Pb}(\mathrm{II})$ is shown in Fig. 3.

Although the peaks corresponding to both lead and cadmium are well resolved, there remains a serious problem as to the shifting of the baseline in this case. It is noted that after each sample injection the problem of tailing increased. It took as long as $24 \mathrm{~h}$ after each injection and in some cases more than $24 \mathrm{~h}$ for the baseline to return to initial zero position. In fact, after several injections the tailing period became so significant that the membrane in the post column reactor (PCR) had to be replaced. Since such a long elution time and cumbersome PCR replacement are

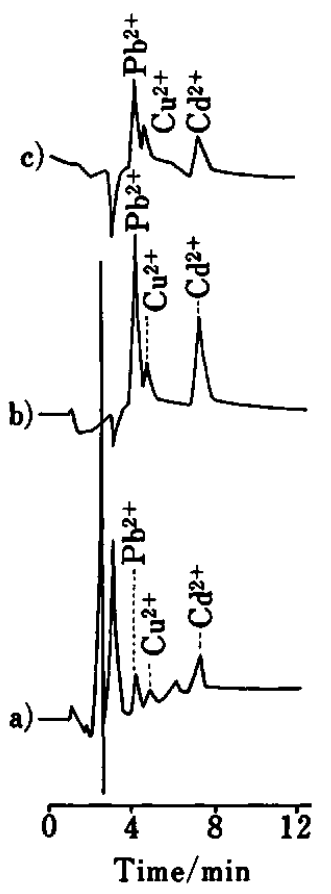

Fig. 2 (a) Ion chromatogram of the electroless plating bath solution using two AS-3 columins. (b) Ion chromatogram of $\mathrm{Pb}(\mathrm{II}), \mathrm{Cd}(\mathrm{II})$ and $\mathrm{Cu}(\mathrm{II})$ solution. $\mathrm{Cu}(\mathrm{II})$ is a low level contaminant in our system. [Pb(II)] and [Cd(II)] are 1.0 $\mathrm{mg} / \mathrm{l}$. (c) Ion chromatogram of $\mathrm{Pb}$ (II), $\mathrm{Cd}$ (II) and $\mathrm{Cu}(\mathrm{II})$ solution. $\mathrm{Cu}(\mathrm{II})$ is a low level contaminant in our system. $[\mathrm{Pb}(\mathrm{II})]$ and $[\mathrm{Cd}(\mathrm{II})]$ are $0.5 \mathrm{mg} / 1$. 
not acceptable for efficient operation, the modifications, as presented in Fig. 4, were performed to overcome these problems.

In both operating modes the eluent flows from the pump into the injector valve. When the valve is in the

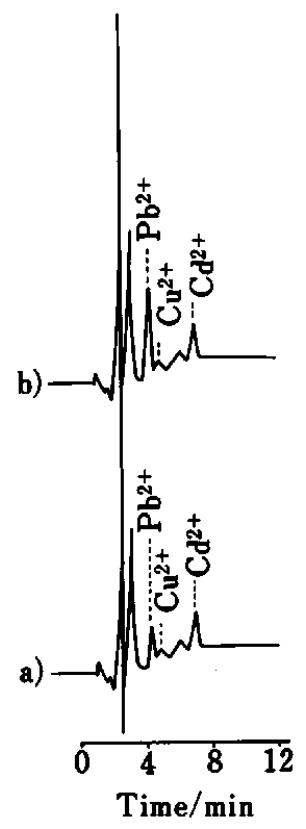

Fig. 3 (a) Ion chromatogram of the electroless plating bath solution using two AS-3 columns. (b) Ion chromatogram of sample (a) when spiked with $0.5 \mathrm{mg} / 1$ of $\mathrm{Pb}$ (II) solution. load position the eluent follows the flow path 1-4, 8-5 to the guard and separator columns. With the valve in the inject position the flow path is $1-2,6-5$.

In the standard operating mode the eluent flows through the column into the membrane reactor where it is mixed with the PAR reagent and then flows to the detector cell and finally to waste.

In the modified operating mode there are two separator columns (A and B) connected in series. In addition, a switching valve has been placed between column $B$ and the membrane reactor. During the separation step of the analysis, the eluent from the columns follows the flow path 10-11 through the switching valve and into the membrane reactor, the detector cell and finally to waste. In the column flushing and equilibration steps the valve is switched in such a way so that the column eluent follows the flow path 10-9-12 leading directly to waste.

In the modified method, upon injection of the sample into the instrument, lead(II) and cadmium(II) are eluted within $10 \mathrm{~min}$. The eluent $0.05 \mathrm{M}$ oxalic acid is then replaced by $0.25 \mathrm{M}$ oxalic acid for the flushing of the column and the major components of the sample. At this time the switching valve is used so that the eluent bypasses the membrane reactor. The column effluent is vented directly to the waste container. After 35 min of elution time, the eluent is replaced with $0.05 \mathrm{M}$ oxalic acid and the switching valve is reset to its original position. The system is allowed to operate under these conditions for a period of additional 15 min. At the end of 50 min total run time, the system is re-equilibrated and ready for injection of the next

a)

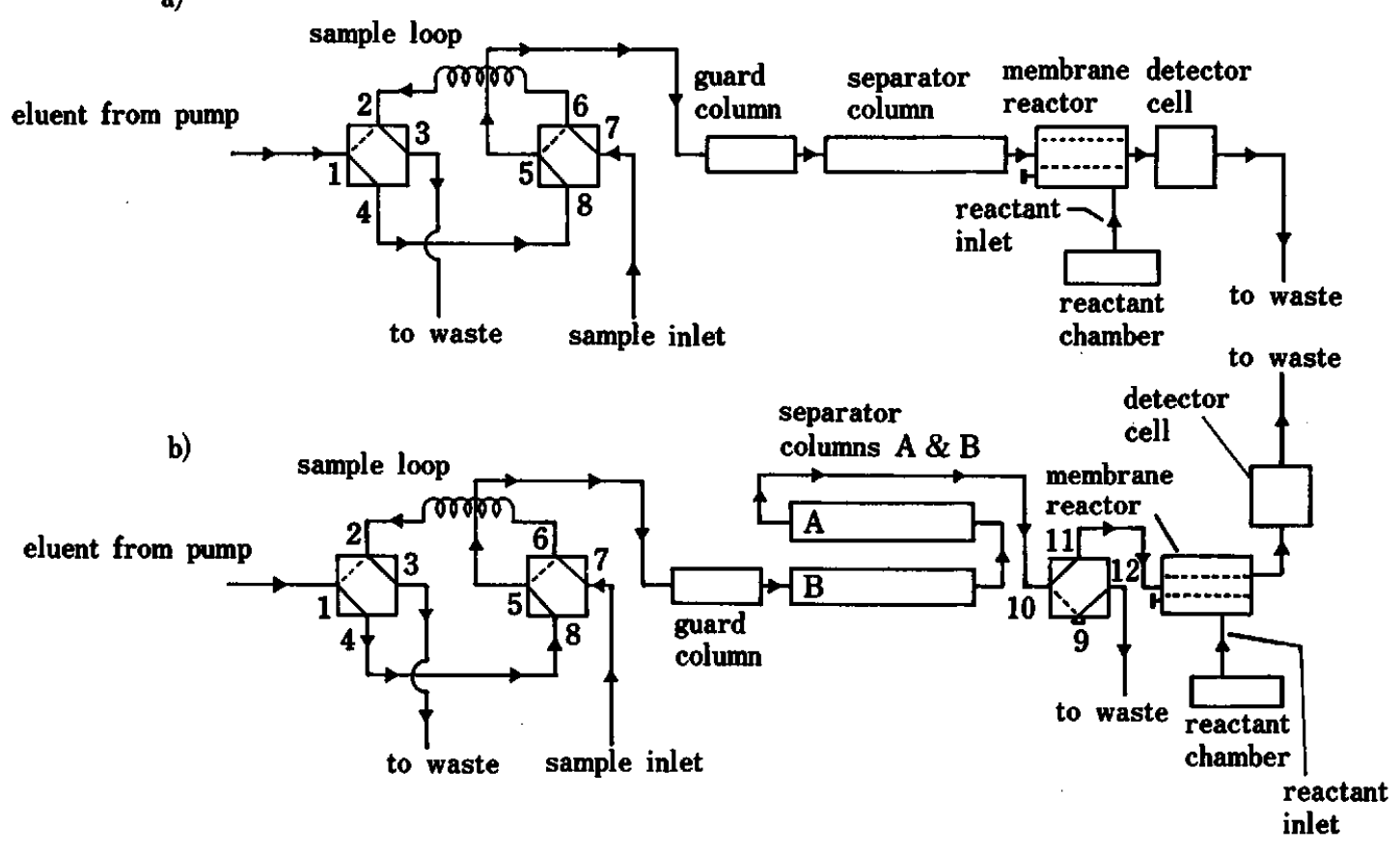

Fig. 4 (a) Standard IC operating diagram. (b) Modified IC operating diagram. 
Table 2 Reproducibility study of standard solutions

\begin{tabular}{cccc}
\hline $\begin{array}{cc}{[\mathrm{Pb}(\mathrm{II})]} \\
1.0 \mathrm{mg} / 1\end{array}$ & $\begin{array}{c}{[\mathrm{Pb}(\mathrm{II})]} \\
0.5 \mathrm{mg} / 1\end{array}$ & $\begin{array}{c}{[\mathrm{Co}(\mathrm{II})]} \\
1.0 \mathrm{mg} / 1\end{array}$ & $\begin{array}{c}{[\mathrm{Cd}(\mathrm{II})]} \\
0.5 \mathrm{mg} / 1\end{array}$ \\
\hline 1.01 & 0.49 & 1.00 & 0.50 \\
0.99 & 0.50 & 0.96 & 0.52 \\
1.02 & 0.52 & 0.99 & 0.49 \\
0.99 & 0.49 & 1.02 & 0.52 \\
1.01 & 0.52 & 1.02 & 0.47 \\
0.99 & 0.50 & 0.99 & 0.48 \\
1.00 & 0.50 & 1.00 & 0.47 \\
1.02 & 0.53 & 1.03 & 0.50 \\
$x=1.00$ & 0.49 & 1.01 & 0.49 \\
\hline
\end{tabular}

sample. It has been found that such a set-up avoids contamination of the membrane and a stable base line can be achieved in less than an hour.

The precision and accuracy of the method was studied with eight replicate injections of each standard and the linearity was checked over the concentration range of interest. The data presented in Table 2 shows that the method is reproducible.

Several bath samples were also analyzed by both ion chromatography and atomic absorption spectroscopy. The results from both techniques appear to be in close agreement as illustrated in Table 3.

In conclusion, by using two ion separator columns (Dionex HPIC AS-3) in series and introducing a simple flushing technique, we have developed a method for determining $\mathrm{Pb}(\mathrm{II})$ and $\mathrm{Cd}(\mathrm{II})$ in presence of higher concentration of $\mathrm{Ni}(\mathrm{II}), \mathrm{Co}(\mathrm{II})$ and $\mathrm{Zn}$ (II) in electroless plating baths. The method is relatively fast, efficient and accurate. It provides an alternative to polarography or atomic absorption spectroscopy for analyzing the plating bath stabilizers in the presence of major bath components.
Table 3 Comparison of data obtained by ion chromatographic (IC) and atomic absorption (AA) analysis

\begin{tabular}{cccccc}
\hline \multirow{2}{*}{ Sample No. } & \multicolumn{2}{c}{$[\mathrm{Pb}(\mathrm{II})] / \mathrm{mg} \mathrm{l}^{-1}$} & & \multicolumn{2}{c}{$[\mathrm{Cd}(\mathrm{II})] / \mathrm{mg} \mathrm{l}^{-1}$} \\
\cline { 2 - 3 } & $\mathrm{AA}$ & $\mathrm{IC}$ & & $\mathrm{AA}$ & $\mathrm{IC}$ \\
\hline 3884 & 0.48 & 0.50 & & 0.30 & 0.45 \\
31484 & 0.30 & 0.20 & & 0.60 & 0.40 \\
4584 & 0.45 & 0.50 & & 0.60 & 0.43 \\
92884 & 0.47 & 0.50 & & 0.05 & 0.10 \\
4184 & $\mathrm{ND}$ & 0.20 & & $\mathrm{ND}$ & 0.10 \\
\hline
\end{tabular}

ND $=$ None Detected

\section{References}

1. S. Heberling, J. Riviello, C. A. Pohl, M. S. Taylor, S. Papanu and M. Ebenhahn, Paper presented at the 26th Rocky Mountain Conference (1984).

2. J. Riviello and C. Pohl, Paper presented at the 25th Rocky Mountain Conference (1983).

3. G. Franklin and J. Lanier, Paper presented at the American Electro-platers Society, Plating and Electrographics Symposium (1984).

4. J. Riviello, Dionex, Ion Chromatography Exchange, 2, 4 (1983).

5. K. Haak, Dionex, Ion Chromatography Exchange, 1, 3 (1983).

6. Applications Note 49, Dionex Corporation (1983).

7. Technical Note 10R, Dionex Corporation (1983).

8. J. Fritz, Liquid Chromatography LC, 2, 446 (1984).

(Received May 2, 1986) (Accepted May 6, 1986) 